\title{
LEVANTAMENTO DOS DADOS DEMOGRÁFICOS DO MUNICÍPIO DE CAMPOS DOS GOYTACAZES/RJ COMO SUBSÍDIOS PARA A PEDAGOGIA DO ENVELHECIMENTO
}

\author{
Paula Rodrigues Mothé \\ Graduanda em Pedagogia/ISECENSA/RJ \\ paulamothe@yahoo.com.br \\ Tamia Lopes Leite \\ Graduanda em Pedagogia/ISECENSA/RJ \\ tamialeite@gmail.com
}

\section{Teresa Claudina de Oliveira Cunha}

Mestre em Comunicação e Cultura/Coordenação de Pedagogia/ISECENSA/RJ

trcocunha@gmail.com

\section{Vânia Machado Seabra Puglia}

Mestre em Comunicação e Cultura/Coordenação de Pedagogia/ISECENSA/RJ vpuglia@gmail.com

\section{RESUMO}

Este estudo disponibiliza um levantamento dos dados demográficos do município de Campos dos Goytacazes/RJ, fator imprescindível para o desenvolvimento de estratégias para a pedagogia do envelhecimento. Atualmente, segundo dados do Censo do IBGE (2010), existem 463.731 pessoas, sendo que o índice de envelhecimento corresponde a $12 \%$ da população total. Este segmento etário está aumentando e configura um desenho demográfico que refletirá nos próximos anos em uma maior população idosa. A investigação partiu de uma pesquisa bibliográfica sobre a questão principal que é o envelhecimento populacional. A pesquisa caracteriza-se como de natureza quantitativa. Levando em consideração o objetivo proposto, tem caráter descritivo e exploratório, na qual foram utilizados dados obtidos dos Censos Demográficos e dos Indicadores Sociais do IBGE, do período de 1991 a 2015. Como resultado, pode-se perceber que o crescimento e o envelhecimento demográfico da população indicam um fenômeno relevante que vem modificando a perspectiva de vida dos indivíduos. O grande desafio que se coloca para a sociedade contemporânea envolve o reconhecimento do ser enquanto sujeito de direitos, dos princípios de independência, participação, dignidade, assistência e autorrealização estabelecidos pela ONU. Nesse sentido, constata-se, principalmente, a relevância da educação, para além de um direito social, mas como possibilidade de mudança de visão em relação ao envelhecimento. Uma pedagogia do envelhecer que envolva uma dinâmica de co-educação(parcerias) que proporcione ao idoso a inserção social, o reconhecimento das condições de sobrevivência e garantias de melhor qualidade de vida, dignidade e cidadania.

Palavras-chave: Levantamento demográfico; Envelhecimento; Pedagogia.

\section{ABSTRACT}

This article provides a demographic analysis about County of Campos dos Goytacazes (Rio de Janeiro State, Brazil), an essential factor on the development of pedagogy strategies for aging. In accordance with IBGE Census' (2010), this County has a 463,731 population and it's aging index corresponding to $12 \%$ of this total. This age segment is increasing and demonstrates a demographic extract that will reflect a large elderly population in the coming years. This article is based on bibliographical research about population aging. The objective is classified as descriptive and exploratory, the data used are from Demographic Census and Social

Persp. online: hum. \& sociais aplicada., Campos dos Goytacazes, 17 (6), 14-21, 2016

seer.perspectivasonline.com.br 
Indicators of IBGE (1991 to 2015 period). The data has a qualitative treatment. The result shows that population is growth and aging and this indicate a relevant phenomenon to society. On this way, this article addresses the need of contemporary society to practice a real inclusion for the elderly, besides the education role in this process of reformulation about the old age understanding.

Key words: Demographic survey; Aging; Pedagogy

\section{INTRODUÇÃO}

A população mundial tem exibido uma significativa reestruturação demográfica, caracterizando-se principamente pela redução das taxas de fecundidade, diminuição da mortalidade e consequente aumento da expectativa de vida. As estruturas etárias dos países vêm apresentando transformações representativas no que se refere, sobretudo, a um aumento na dimensão de adultos e idosos no conjunto da população.

Essa realidade vem, nos últimos anos, ocupando cada vez mais um espaço de investigação das diversas áreas de conhecimento. Segundo o índice de envelhecimento, definido como sendo o número de pessoas de 60 ou mais anos de idade, para cada 100 pessoas menores de 15 anos de idade, na população residente em determinado espaço geográfico, no ano considerado, vem em um contínuo e crescente aumento.

Este fenômeno se faz presente nas sociedades indistintamente do grau de desenvolvimento e, um dos grandes desafios delineados para o século XXI é equacionar as reais necessidades deste emergente perfil populacional, preocupando-se com a garantia de direitos e de qualidade de vida. (OLIVEIRA, 2012, p. 2)

O envelhecimento, portanto, tem sido um importante tema na sociedade contemporânea, o que vem demandando políticas e ações universais que busquem a garantia dos direitos sociais do idoso, com vista à promoção da autonomia, integração e participação efetiva na sociedade.

O envelhecimento é uma questão atual e demanda uma série de medidas que garantam à pessoa idosa direitos. A Organização das Nações Unidas (ONU), por meio de uma ação de cooperação entre os países, construiu Planos de Ação Internacionais para o Envelhecimento (ONU/1982) que constituem o primeiro instrumento internacional sobre a questão do envelhecimento. Eles indicam, para todas as sociedades, princípios para a organização e a formulação de políticas e programas sobre o tema envelhecimento. O plano reúne um conjunto de recomendações para o desenvolvimento de ações nas seguintes áreas: saúde e nutrição, proteção de consumidores idosos, habitação e meio ambiente, família, bem-estar social, segurança de renda e emprego, educação e a coleta e análise de dados de investigação.

Segundo a Organização Pan-Americana de Saúde (2005, p. 14), o envelhecimento fundamenta-se no "reconhecimento dos direitos humanos das pessoas idosas e nos princípios de independência, participação, dignidade, assistência e autorrealização estabelecidos pela ONU" (ORGANIZAÇÃO PAN-AMERICANA DE SAÚDE, 2005, p. 14).

A Organização Pan-Americana da Saúde (OPAS, 2005) afirma também ser a idade cronológica um fator relevante no processo do envelhecimento de uma população, no entanto, reconhece a existência de outros fatores ou aspectos tais como o biológico, psicológico e social.

- Envelhecimento biológico (PAPALÉO, 2002; SALGADO, 1982) é o tempo de vida humana que o organismo sofre consideráveis mutações de declínio na sua força, disposição e aparência, as quais não incapacitam ou comprometem o processo vital. É o envelhecimento considerado natural, onde o organismo apresenta alterações funcionais, atribuídas ao envelhecimento, que são próprias do avançar dos anos.

- Envelhecimento psicológico (GATTO, 2002; SALGADO, 1982) diz respeito aos aspectos cognitivos e às emoções, que estão diretamente relacionadas com as questões sociais, com o contexto socioambiental que o indivíduo está inserido.

Persp. online: hum. \& sociais aplicada., Campos dos Goytacazes, 17 (6), 14-21, 2016

seer.perspectivasonline.com.br 
- Envelhecimento social é a dimensão construída pela sociedade. Nas sociedades antigas, em geral, ser velho conferia uma posição dignificante e todos que atingiam essa etapa eram acatados como sábios. Nas sociedades contemporâneas, na sua maioria, ser velho significa estar excluído de vários lugares sociais. Um desses lugares é aquele relativo ao mundo do trabalho. (...) A inadaptação do idoso aos padrões ideais estabelecidos pela sociedade, como a perda do papel profissional com a aposentadoria e a perda do papel na família como chefe de família e provedor, conduz ao isolamento, onde o idoso vai diminuindo seus contatos com o mundo em que vive, surgindo sentimentos de inutilidade e solidão, levando à depressão e muitas vezes à morte. (CARVALHO, 2007, p. 14-15)

Segundo Closs e Schwanke (2012, p. 444), hoje, pessoas com 60 anos ou mais de idade representam um significativo contingente populacional, "em termos absolutos e de crescente importância relativa no conjunto da sociedade brasileira, daí decorrendo uma série de novas exigências e demandas em termos de políticas públicas de saúde e inserção ativa dos idosos na vida social.”

No Brasil, o processo de envelhecimento reforça o contexto internacional, na medida em que o número de idosos no país apresenta um crescente aumento. Segundo dados da Pesquisa Nacional por Amostra de Domicílios, referentes ao segundo trimestre de 2016, que têm como objetivo principal traçar o perfil da população em idade de trabalhar, a força de trabalho ocupada e desocupada e fora da mercado de trabalho, o contexto indica que

as pessoas de 14 a 17 anos de idade representavam 8,4\% das pessoas em idade de trabalhar. Os jovens de 18 a 24 anos correspondiam a 13,4\%, enquanto o grupo etário de 25 a 39 anos, 28,7\%. A maior parcela era a daqueles do grupo de 40 a 59 anos $(31,7 \%)$. Os considerados idosos pela Organização Mundial da Saúde para países em desenvolvimento, 60 anos ou mais de idade, representavam 17,9\%. Esse grupo etário tem apresentado crescimento desde o início da série ( $1^{\circ}$ trimestre de 2012 ), quanto correspondia a $15,9 \%$ da população total.

É importante observar que a composição etária era diferente entre as cinco Grandes Regiões, característica importante para o entendimento do mercado de trabalho regional. Na Região Norte, a parcela das pessoas de 14 a 17 anos era bem próxima a de idosos, fato não observado nas demais regiões. Outro destaque, também observado na Região Norte, é o fato da participação da população de 18 a 24 anos ser superior à de idosos. Ressalta-se ainda que as Regiões Sudeste $(19,4 \%)$ e Sul $(19,3 \%)$ apresentaram os maiores percentuais de idosos. (Instituto Brasileiro de Geografia e Estatística - IBGE, 20016, p. 7-8)

Os dados retratam, portanto, a significativa demanda social que se apresenta para as ciências humanas e sociais na realização de estudos e pesquisas sobre o processo de envelhecimento e a necessidade de se desenvolver ações propositivas que atendam aos pilares estabelecidos pela ONU, que são o reconhecimento dos direitos humanos, princípios de independência, cidadania, participação na sociedade, dignidade, assistência e autorrealização.

Órgãos oficiais, como o Instituto Brasileiro de Geografia e Estatística - IBGE -, disponibilizam, por meio de indicadores sociais e demográficos, dados e informações imprescindíveis para uma melhor percepção e compreensão do processo de envelhecimento populacional que tem caracterizado a sociedade brasileira contemporânea.

O processo de envelhecimento pelo qual passa a população brasileira tem direcionado o Estado a organizar e fortalecer, com a máxima urgência, as políticas públicas de proteção e promoção dos direitos da pessoa com 60 ou mais anos de idade. No Brasil, diante da necessidade de se estabelecer uma política de assistência e promoção social, surge a Política Nacional do Idoso, estabelecida em 1994, por meio da Lei 8.842, aspirando à promoção da longevidade com qualidade de vida, com ações direcionadas não exclusivamente para os idosos, mas para toda a população que está inserida no processo de envelhecimento. Essa política tem por objetivo "assegurar os direitos sociais do idoso, criando condições para promover sua autonomia, integração e participação efetiva na sociedade" (artigo $1^{\circ}$ da lei).

Persp. online: hum. \& sociais aplicada., Campos dos Goytacazes, 17 (6), 14-21, 2016

seer.perspectivasonline.com.br 
O documento legal, denominado Estatuto do Idoso, instituído conforme a Lei $n^{\circ} 10741 / 2003$, determina fundamentos ou princípios que vão regular os direitos da pessoa com idade igual ou superior a 60 anos. Esta lei surge para garantir, especificamente para a pessoa idosa, direitos fundamentais no que diz respeito às suas condições de saúde, dignidade e bem-estar. Acima de tudo, representa um movimento que envolve dimensões fundamentais para que esses sujeitos possam conquistar uma cidadania plena na sociedade. Desta forma, segundo Henrique Eduardo Alves (2013, p. 9), "os idosos poderão exigir o respeito à lei e dela se beneficiar, e os mais jovens poderão assumir as responsabilidades dela decorrentes." Em seu artigo $2^{\circ}$, a lei determina que:

O idoso goza de todos os direitos fundamentais inerentes à pessoa humana, sem prejuízo da proteção integral de que trata esta lei, assegurando-se-lhe, por lei ou por outros meios, todas as oportunidades e facilidades, para preservação de sua saúde física e mental e seu aperfeiçoamento moral, intelectual, espiritual e social, em condições de liberdade e dignidade.

Para tanto, fazem-se necessários o planejamento e o desenvolvimento de políticas, programas e projetos que considerem os interesses dos idosos e para que essa população tenha garantido os seus direitos.

Pensar em uma pedagogia do envelhecimento significa compreender que o ponto fundamental é o desenvolvimento de estratégias de ensino que reconheçam que o que interessa é o que o idoso quer, que o tornem novamente uma pessoa ativa, competente, capaz de gestar sua vida (PIRES; LIMA, 2007, p. 410 apud RODRIGUES, 1999), possibilitando ao indivíduo o enfrentamento de questões que envolvem a sua estrutura social, econômica, política e cultural.

Idosos continuam aprendendo por que centram sua aprendizagem no que é de seu interesse, considerando que a vontade de aprender é a principal auxiliar da aprendizagem e que as pessoas que estão sempre ativas nas tarefas intelectuais ou físicas conservam essa capacidade ao longo de sua vida. (PIRES; LIMA, 2007, p. 408)

Segundo Sobral (2001, p. 67), a educação em terceira idade deve ser fundamentada por "uma filosofia de trabalho educativo de cunho emancipatório, projetado para liberar as pessoas de atitudes e antigas suposições que limitam o potencial e não permitem a criação de possibilidades mais positivas para o crescimento pessoal. O central na educação emancipatória é a aquisição de conhecimentos para a transformação pessoal".

A professora Vera Candau (2009, p. 71) afirma ser importante

favorecer o processo de "empoderamento" ("empowerment"), principalmente orientado aos atores sociais que historicamente tiveram menos poder na sociedade, isto é, poucas possibilidades de influir nas decisões e nos processos coletivos. O "empoderamento" começa por liberar as possibilidades, a potência que cada pessoa tem para que ela possa ser sujeito de sua vida e ator social. O "empoderamento" tem também uma dimensão coletiva. Trabalha na perspectiva do reconhecimento e valorização dos grupos socioculturais excluídos e discriminados, favorecendo sua organização e participação ativa na sociedade civil.

Uma pedagogia do envelhecer que envolva uma dinâmica de co-educação (parcerias) que proporcione "ao idoso uma qualidade de vida, resgate do sentido de velhice, despertando-o e desenvolvendoo e estimulando-o segundo sua capacidade, suas aptidões esquecidas, para se tornar um cidadão competente para entender a sua velhice. ” (PIRES; LIMA, 2007, p. 411)

No Brasil, o envelhecimento humano é um assunto recente e cada vez mais valorizado, pois, com o avanço da medicina e com a queda da mortalidade, houve o aumento da população com mais de sessenta anos. Com isso, ocorreu a necessidade de a sociedade e de o governo darem uma maior atenção ao público desta faixa etária. Segundo a Organização Pan-Americana de Saúde (2005, p. 14), o envelhecimento fundamenta-se no "reconhecimento dos direitos humanos das pessoas idosas e nos princípios de

Persp. online: hum. \& sociais aplicada., Campos dos Goytacazes, 17 (6), 14-21, 2016

seer.perspectivasonline.com.br 
independência, participação, dignidade, assistência e autorrealização estabelecidos pela ONU" (ORGANIZAÇÃO PAN-AMERICANA DE SAÚDE, 2005, p. 14).

Segundo Pimentel e Lamarca (2012)

Estima-se que atualmente, cerca de um milhão de pessoas cruza a barreira dos 60 anos de idade, a cada mês, em todo o mundo e que até 2025, a população idosa do planeta crescerá $2,4 \%$ ao ano, contra $1,3 \%$ de crescimento anual da população terrestre em sua totalidade. $\mathrm{O}$ número de idosos deve duplicar até 2050 , alcançando $15 \%$ do total da população. No caso do Brasil, especificamente, tanto a questão da violência quanto a própria característica demográfica de crescimento, apontam para urgências ligadas a preparação de profissionais especializados no trato com idosos, reforço na atenção básica a saúde e planejamento urbano.

Por mais que leis recentes tenham dado uma atenção significativa à violência contra os idosos, na sua prática, elas ainda apresentam dificuldades para solucionar os conflitos entre os homens, problemas tão latentes na sociedade. Somente por meio da recuperação da dignidade do indivíduo é que esses problemas terão a possibilidade de serem resolvidos, diante do reconhecimento de sua participação como cidadão e com a eficácia da implantação dos princípios que as leis comunicam.

Este estudo e investigação têm como objetivo principal levantar o perfil demográfico do município de Campos dos Goytacazes/RJ, fator imprescindível para o desenvolvimento de estratégias para a pedagogia do envelhecimento.

\section{METODOLOGIA}

No presente estudo, realizou-se uma pesquisa bibliográfica sobre a questão principal que é o envelhecimento populacional. A pesquisa caracteriza-se como de natureza quantitativa. Levando em consideração o objetivo, tem caráter descritivo e exploratório, na qual serão utilizados dados obtidos dos Censos Demográficos e dos Indicadores Sociais do IBGE, do período de 1991 a 2015, a principal fonte de informações para a análise.

A metodologia adotada envolveu levantamentos de dados secundários e primários e contempla os seguintes passos:

1. Levantamento e revisão bibliográfica e documental: consulta a livros, periódicos, relatórios de pesquisa e sites na internet.

2. Levantamento de fontes de dados primários: coleta de dados em sites oficiais.

3. Tratamento, cruzamento e análise dos dados estatísticos obtidos.

4. Definição de variáveis e indicadores a serem mapeados no desenvolvimento da pesquisa.

\section{RESULTADOS E ANÁLISE DOS DADOS}

A análise dos dados apresentados a seguir, mesmo que de forma sucinta, retrata e aponta (expectativas) o avanço no índice de envelhecimento no Brasil, tendo como recorte o município de Campos dos Goytacazes/RJ.

Persp. online: hum. \& sociais aplicada., Campos dos Goytacazes, 17 (6), 14-21, 2016

seer.perspectivasonline.com.br 


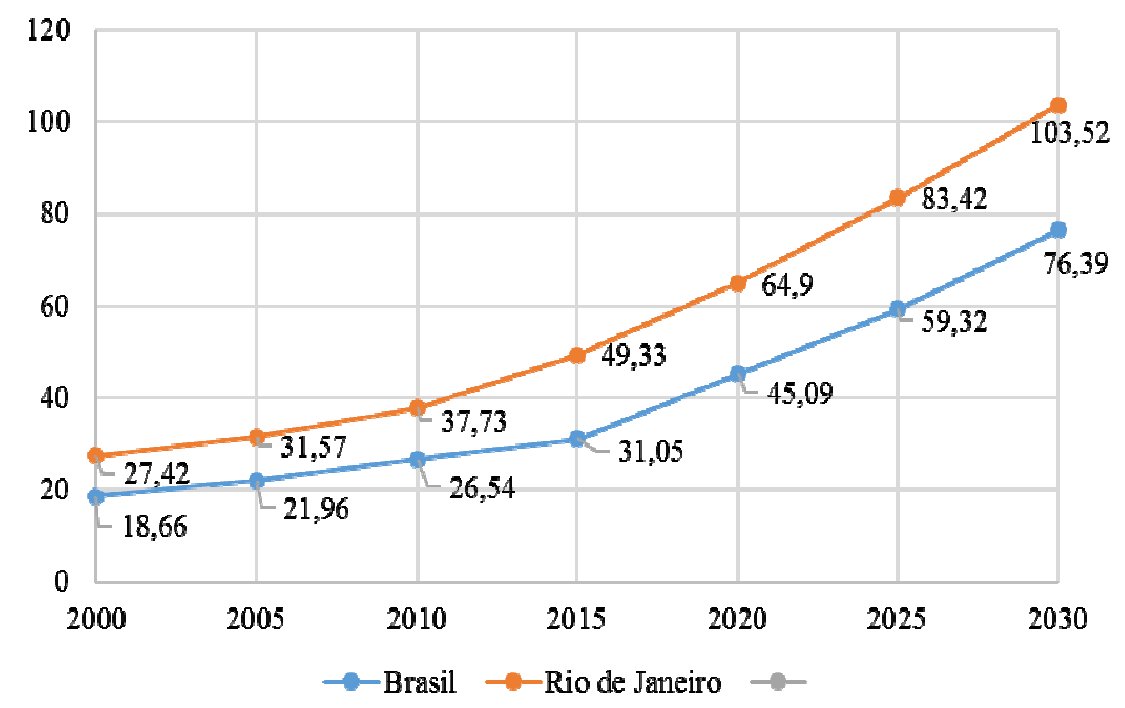

Figura 1: Índice de Envelhecimento (IE), Brasil e Rio de Janeiro - 2000 - 2030.

Fonte: Projeção da população do Brasil e das Unidades da Federação, IBGE. Disponível em:

$<$ http://www.ibge.gov.br/apps/populacao/projecao/>. Acesso em: 11 out. 2016.

A Figura 1 mostra o desenho demográfico do envelhecimento populacional no Brasil e, especificamente no Estado do Rio de Janeiro, durante o período de 2000 a 2030. Retrata o crescimento do índice de envelhecimento, bem com a expectativa de um aumento significativo até 2030.

A Figura 2 apresenta o desenho demográfico populacional, por gênero, do município de Campos dos Goytacazes/RJ, durante o período de 1991-2010. Pode-se observar uma taxa média de crescimento anual da década de 1991 (376.496 pessoas) a 2000 (407.118 pessoas) de aproximadamente 0,87\%. Na década seguinte, 2000 a 2010 (463.731 pessoas), o crescimento corresponde a 1,31\%. Segundo dados do IBGE, a população estimada neste ano é de 487.186 pessoas.

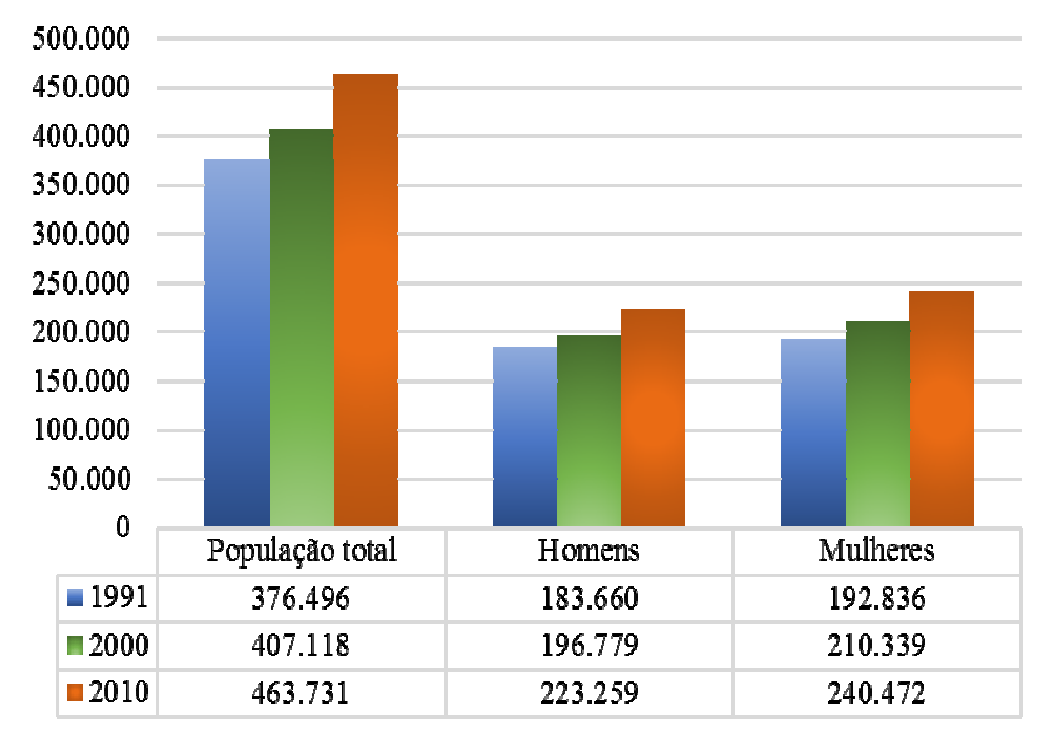

Figura 2: População Total, por gênero, do município de Campos dos Goytacazes, 1991-2010 Fonte: Atlas do Desenvolvimento Humano no Brasil, 2013.

Estudos e pesquisas indicam também a demografia populacional do município com relação à estrutura etária. Assim como na realidade do país, o número de idosos está crescendo no município de Campos dos Goytacazes/RJ. A Figura 3 apresenta a estrutura etária do município entre 1991 e 2010.

Persp. online: hum. \& sociais aplicada., Campos dos Goytacazes, 17 (6), 14-21, 2016 


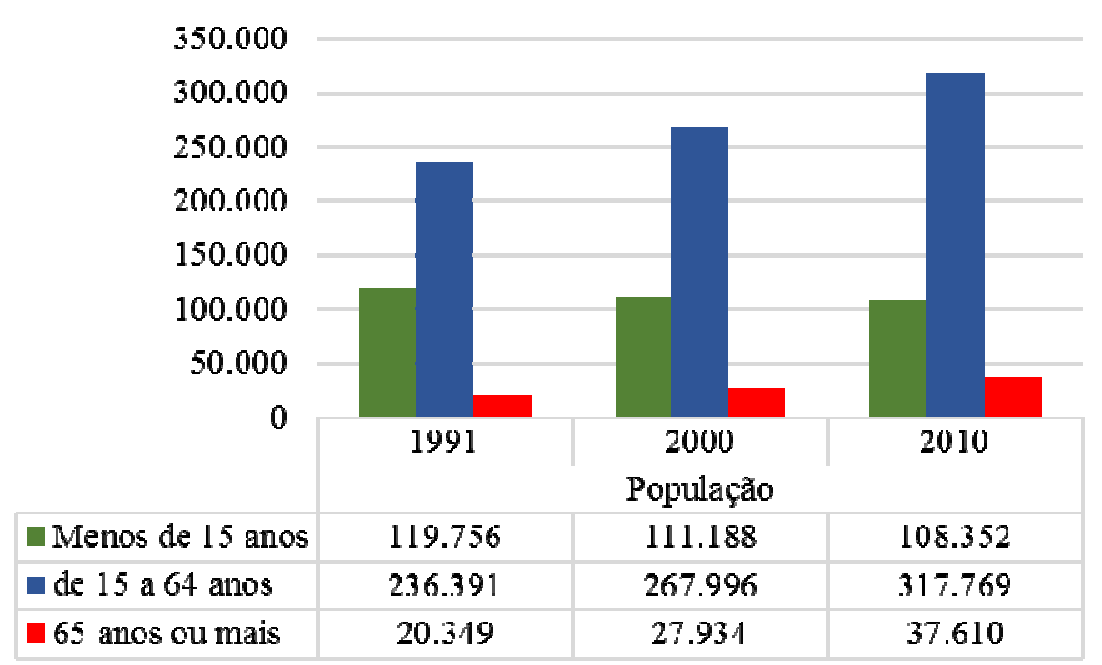

Figura 2: Estrutura Etária da População - Campos dos Goytacazes, 1991-2010. Fonte: Atlas do Desenvolvimento Humano no Brasil, 2013.

Analisando os dados coletados com relação à estrutura etária do município (Figura 3). Pode-se identificar na Tabela 1, a ocorrência de um aumento no índice de envelhecimento de uma década para outra. Observa-se, portanto, que o número de idosos está aumentando continuamente, corroborando a tese de que a população brasileira está envelhecendo.

Tabela 1: Índice de Envelhecimento no Município de Campos dos Goytacazes, 1991 - 2010

\begin{tabular}{c|r|r|r}
\hline \multirow{2}{*}{$\begin{array}{c}\text { Índice de } \\
\text { envelhecimento }\end{array}$} & \multicolumn{3}{|c}{ Ano } \\
\cline { 2 - 4 } & 1991 & 2000 & 2010 \\
\cline { 2 - 4 } & $5,40 \%$ & $6,86 \%$ & $8,11 \%$ \\
\hline
\end{tabular}

Hoje, no Brasil, segundo a Síntese de Indicadores Sociais: uma análise das condições de vida da população brasileira $2015,13,7 \%$ da população tem mais de 60 anos. No município de Campos dos Goytacazes, segundo Censo IBGE 2010, o índice corresponde a 12\% da população total.

\section{CONCLUSÕES}

O estudo e a investigação possibilitaram o conhecimento do índice de envelhecimento da população do município de Campos dos Goytacazes/ RJ, apresentando que o segmento etário com 60 ou mais idade está crescendo continuamente. $\mathrm{O}$ crescimento e envelhecimento demográfico, portanto, indicam um fenômeno relevante que vem modificando a perspectiva de vida dos indivíduos.

O grande desafio que se coloca para a sociedade contemporânea envolve o reconhecimento do ser enquanto sujeito de direitos, dos princípios de independência, participação, dignidade, assistência e autorrealização estabelecidos pela ONU. Nesse sentido, constata-se, principalmente, a relevância da educação, para além de um direito social, mas como possibilidade de mudança de visão em relação ao envelhecimento.

A construção de uma educação permanente que permita o desenvolvimento integral do idoso, enquanto um processo biológico, psicológico e social. Uma pedagogia do envelhecimento que compreenda, acima de tudo, uma nova concepção de vida, que oportunize a inserção ativa dos idosos na vida social.

Uma pedagogia voltada para uma concepção, elaboração e implementação de programas de motivação, estimulação, crescimento pessoal e de formação voltados para a população idosa.

Persp. online: hum. \& sociais aplicada., Campos dos Goytacazes, 17 (6), 14-21, 2016

seer.perspectivasonline.com.br 


\section{REFERÊNCIAS}

BRASIL. Lei 8.842, de 4 de janeiro de 1994. Dispõe sobre a Política Nacional do Idoso, cria o Conselho Nacional do Idoso e dá outras Providências. Diário Oficial [da] República Federativa do Brasil. Brasília, DF, 5 jan. 1994.

BRASIL. Lei n. 10.741, de $1^{\circ}$ de outubro de 2003. Dispõe sobre o Estatuto do Idoso e dá outras providências. Diário Oficial da União, Brasília, 3 out. 2003. Seção 1, p. 1.

CANDAU, Vera Maria. Educação em direitos humanos e diferenças culturais: questões e buscas-DOI: http://dx. doi. org/10.15603/1982-8993/ml. v2n1p65-82. Múltiplas Leituras, v. 2, n. 1, p. 65-82, 2009. Disponível em: <https://www.metodista.br/revistas/revistas-ims/index.php/ML/index >. Acesso em: 17 out. 2016.

CARVALHO, Maria Clotilde Barbosa Nunes Maia de. O diálogo intergeracional entre idosos e crianças: projeto "era uma vez... atividades intergeracionais". Dissertação (Mestrado em Serviço Social) Pontifícia Universidade Católica do Rio de Janeiro, Rio de Janeiro, 2007. Disponível em: $<$ http://www.maxwell.vrac.puc-rio.br/11345/11345_1.PDF>. Acesso em: 15 set. 2016.

CLOSS, Vera Elizabeth; SCHWANKE, Carla Helena Augustin. A evolução do índice de envelhecimento no Brasil, nas suas regiões e unidades federativas no período de 1970 a 2010 . Rev. bras. geriatr. gerontol., Rio de Janeiro , v. 15, n. 3, p. 443-458, Sept. 2012 . Disponível em: $<$ http://www.scielo.br/scielo.php?script=sci_arttext\&pid=S1809-98232012000300006\&lng=en\&nrm $=$ iso $>$. Acesso em: 16 out. 2016.

OLIVEIRA, Rita de Cássia da Silva. A pesquisa sobre o idoso no Brasil: diferentes abordagens sobre educação nas teses e dissertações (de 2000 a 2009). In: Acta Scientiarum. Education, Maringá, v. 35, n.1, p. 79-87, jan./jun. 2013. Disponível em: . Acesso em: 10 out. 2016.

PIRES, Lenísia Silva et al. O Pedagogo e a Pedagogia do Envelhecer.Fragmentos de Cultura, v. 17, n. 2, p. 403-419, 2007. Disponível em: <http://revistas.ucg.br/index.php/fragmentos/article/view/284/228>. Acesso em: 02 out. 2016.

SOBRAL, Benigno. O trabalho educativo na terceira idade: uma incursäo teórico-metodológica. Textos envelhecimento, v. 3, n. 5, p. 67-91, 2001. Disponivel em: $<\mathrm{http}$ ://revista.unati.uerj.br/scielo.php?script=sci_arttext\&pid=S1517-59282001000100004\&lng $=$ pt\&nrm=iss\&tlng=pt $>$. Acesso em: 10 out. $201 \overline{6}$.

WORLD HEALTH ORGANIZATION. Envelhecimento ativo: uma política de saúde. Tradução por Suzana Gontijo. Brasília: Organização Pan-Americana da Saúde, 2005. Disponível em: $<$ http://bvsms.saude.gov.br/bvs/publicacoes/envelhecimento_ativo.pdf $>$. Acesso em: 15 set. 2016. 